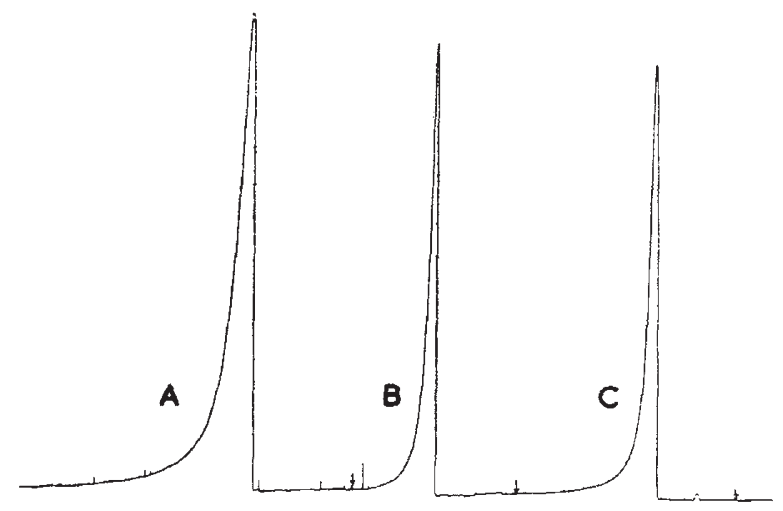

Fig. 1. Chromatograms obtained with aniline on packing prepared from $(A)$, untreated 'Embacel'; $(B)$, packing $(A)$ treated in situ with hexamethyldisilazane; and $(C)$, pre-treated ' $m$ mbacel'. Conditions: $0^{\circ} 4 \mathrm{~cm} \times$ $185 \mathrm{~cm}$ column packed with 10 per cent 'Apiezon $L$ ' on 'Embacel' flame ionization detector

The superiority of the in situ treatment is more clearly indicated by a comparison of the ratio of peak height to width at 2 per cent of height. This ratio is 3.86 for the untreated column $(A), 5 \cdot 68$ for the pre-treated column $(C)$, but reaches the value of 9.18 for the column $(B)$ treated in situ.

The in situ treatment of a more actively adsorbing support is even more striking in its effect. A column packed with 10 per cent 'Apiezon $L$ ' on 'Sterchamol' and operated under the same conditions as in Fig. 1 retained aniline and 0 -cresol indefinitely (more than $2 \mathrm{~h}$ ); in situ treatment with hexamethyldisilazane allowed normal elution in 32 and 38 min respectively.

Naturally the new method can only be used when the stationary phase is itself free from polar groups, but this is not a serious limitation in practice, since adsorption by the support is less serious when a polar stationary phase is present; presumably the latter is preferentially adsorbed at the active centres.

Finally, the in situ use of hexamethylsilazane is also of value in reconditioning a column which has become contaminated with sample residues; such contamination often gives rise to a noisy baseline, and otherwise necessitates replacement of the column.

E. P. Atkinson

G. A. P. TUEY

Research Laboratories,

May and Baker, Ltd.

Dagenham, Essex.

'Kwantes, A., and Rijnders, G. W. A., Gas Chromatography, edit. by Desty, D. H., 125 (Butterworths, London, 1958).

${ }^{2}$ Horning, E. C., Moscatelli, E. A., and Sweely, C. C., Chem. and Indust., 25, 751 (1958).

${ }^{3}$ Crowe, P. F., and Hornstein, I., Anal. Chem., 33, 310 (1961).

- Akshinshaya, N. V., et al., Zhuv. fiz. Khim., 36, 1121 (1962).

${ }^{5}$ Kiselev, A. V., et al., Zhuv. fiz. Khim., 35, 1889 (1961).

' Bohemen, J., Langer, S. H., Perrett, R. H., and Purnell, J. H., J. Chem. Soc., 2444 (1960)

\section{Electron Affinity of Tetracyanoethylene}

THE compound tetracyanoethylene (TCNE) has frequently been reported to be one of the strongest known Lewis acids. We have examined the elcetron affinity of TCNE using a modified form of the magnetron previously described ${ }^{1}$.

A copious ion current was observed in the temperaturerange investigations $\left(1,500^{\circ}-1,750^{\circ} \mathrm{K}\right)$, and at the lower temperature this ion current was some 20 times as large as the electron current. A preliminary analysis of the results indicates that the olectron affinity is in the region of $150 \mathrm{kcal}(6.5 \mathrm{eV})$. We attribute this extremely high value to the interaction of the electron with the octupole formed by the four cyanide groups.
This result is interesting in that the value found is greater than the work function of most metals. It is. however, to be stressed that the figure reported here is only a preliminary one, although it is correct as to order of magnitude.

F. M. Page

J. KAY

Department of Chemistry,

College of Advanced Technology,

Gosta Green,

Birmingham 4.

${ }^{1}$ Trans. Farad. Soc., 56, 1742 (1960).

\section{Five-Co-ordinate Compounds of Cobalt}

Most complex compounds of cobalt are of oxidation state +3 and six-co-ordinate, or of oxidation state +2 and four-or six-co-ordinate. Until recently, only a few apparently five-co-ordinate complexes had been reported ${ }^{1}$. These were the anions $\left[\mathrm{Co}(\mathrm{CN})_{5}\right]^{3-}$ and $\left[\mathrm{Co}(\mathrm{CN})_{5}\right]^{2-}$, and the oxygen-carrying Schiff's base compounds $(A)$ and $(B)$.

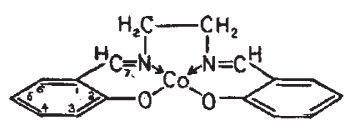

(A)

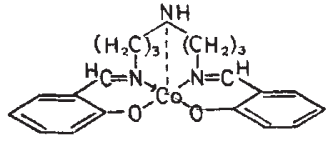

(B)
Formula $(A)$ shows the planar four-co-ordinate configuration suggested by Calvin et al. ${ }^{2}$, but Diehl ${ }^{1}$ believed that the true structure was five-co-ordinate with a water molocule bridging two cobalt atoms. However, tetrahedrally disposed bonds around the bridging oxygen atom would prevent the parallel arrangement of molecules of (A) deduced from X-ray evidence ${ }^{2}$. In addition, Ueno and Martell ${ }^{3 a}$ do not report any infra-red absorptions due to water in the compound and this is supported by other investigations $^{3 b}$. There is no direct proof that the secondary amino group in $(B)$ is co-ordinated to the cobalt atom. The cobaltocyanide ion, in the solid state, has been found to be dimeric, with cobalt-cobalt bonds ${ }^{4}$. and in aqueous solution is probably $\left[\mathrm{Co}(\mathrm{CN})_{5} \mathrm{H}_{2} \mathrm{O}\right]^{3-}$. The compound first reported to be $\mathrm{Ag}_{2} \mathrm{Co}(\mathrm{CN})_{5}$ (ref. 5) is now believed to contain bridging cyanide groups ${ }^{6}$. So perhaps none of these compounds contains five-co-ordinate cobalt.

Many other five-co-ordinate compounds of cobalt have now been reported, but a detailed X-ray examination has been carried out only on nitrosyl(dimethyldithiocarbonato) cobalt (I) (ref. 7), which has the square pyramidal structure $(C)$ with the $\mathrm{N}-\mathrm{O}$ bond inclined at $139^{\circ}$ to the pyramidal axis and forming an unsymmetrical $\pi$-complex with the cobalt atom.

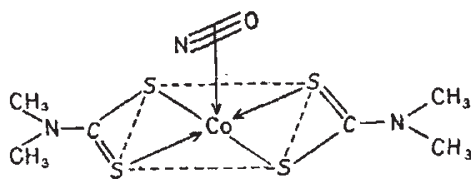

(C)

Other apparently five-co-ordinate compounds are: $\mathrm{Co}^{\mathrm{III}}\left(\mathrm{PEt}_{3}\right)_{2} \mathrm{Cl}_{3}$ (ref. 8) ${ }^{*}, \mathrm{Co}^{11} \mathrm{MeAs}\left[\left(\mathrm{CH}_{2}\right)_{3} \mathrm{AsMe}_{2}\right]_{2} \mathrm{I}_{2}$ (ref. $9 a) *, \mathrm{CoIIMeAs}\left[\left(\mathrm{CH}_{2}\right)_{3} \mathrm{AsMe}_{2}\right]_{2} \mathrm{Br}_{2}$ (ref. 9b) ${ }^{*}, \mathrm{CoII}(\mathrm{CN} R)_{5}{ }^{2-}$ (ref. 10), $\mathrm{Co}^{1}(\mathrm{CNR})_{5}{ }^{+}$(refs. 10, 17), $\left.\mathrm{Co}^{\mathrm{I}}(\mathrm{PR})_{3}\right)_{2}(\mathrm{CO})_{3}{ }^{+}$(ref. 11), $\mathrm{CoIBr}_{2}\left[\mathrm{PH}\left(\mathrm{C}_{6} \mathrm{H}_{5}\right)_{2}\right]_{3}$ (ref. 12), $\mathrm{CoII} X_{2}(\mathrm{CO})\left(\mathrm{PEt}_{3}\right)_{2}$, * $\mathrm{Co}^{\mathrm{I}} X_{2}(\mathrm{NO})\left(\mathrm{PEt}_{3}\right)_{2}, * X=\mathrm{F}, \mathrm{Cl}, \mathrm{Br}^{13}, \mathrm{Co}^{1}(\text { acetylacetone })_{2}$ (NO) (ref. 14)*, and [CoII $(8 \text {-aminoquinoline })_{2}$ (NO) $]_{2}$ (ref, 15)*. Their likely configurations are square (or tetragonal) pyramidal, and trigonal bipyramidal ${ }^{16}$. Compounds marked with an asterisk have boon assigned pyramidal structures. No detailed account of the first compound in the list has appeared, and the last is unusual in containing cobalt (III) and co-ordinated $\mathrm{NO}^{-}$. 